Vol. 2, No. 1, Desember 2021

\title{
PENINGKATAN NILAI EKONOMI HASIL PERKEBUNAN (PISANG) MENJADI PRODUK OLAHAN (PERMEN JELLY) UNTUK MENINGKATKAN PENDAPATAN MASYARAKAT DI DESA KOTARAJA KECAMATAN SIKUR LOMBOK TIMUR
}

\author{
Siti Aisyah Hidayati \\ Fakultas Ekonomi dan Bisnis Universitas Mataram \\ sitiaisyahhidayati@unram.ac.id \\ Sri Wahyulina \\ Fakultas Ekonomi dan Bisnis Universitas Mataram \\ sriwahyulina@yahoo.co.id \\ Embun Suryani \\ Fakultas Ekonomi dan Bisnis Universitas Mataram \\ embunsur74@gmail.com \\ Gusti Ayu Sri Oktariyani \\ Fakultas Ekonomi dan Bisnis Universitas Mataram \\ oktaryani@gmail.com
}

\section{Info Artikel}

Diterima:

04-11-2021

Direvisi:

28-12-2021

Diterbitkan:

28-12-2021

\begin{abstract}
Abstrak
Pisang merupakan komoditas hortikultura (buah) yang dapat dimakan langsung atau diolah. Namun tentunya pengkonsumsian pisang secara langsung ataupun diolah memiliki kelebihan masing-masing. Di Desa Kotaraja masih banyak mengkonsumsi pisang dalam keadaan segar ataupun pengolahan yang masih sederhana seperti direbus dan digoreng. Untuk itu perlu adanya upaya diversifikasi dan peningkatan nilai ekonomi pangan olahan berbahan baku pisang menjadi produk olahan, salah satunya yaitu permen Jelly.

Metode pelaksanaan dilakukan dengan sosialisasi dan praktik pembuatan permen jelly. Sosialisasi pembuatan permen jelly dari pisang dilakukan dihadapan ibu-ibu rumah tangga Kelompok Dasa Wisma di Desa Kotaraja. Kegiatan sosialisasi ini memberikan penjelasan tentang peningkatan nilai ekonomi pisang. Untuk dapat meningkatkan nilai ekonomi harus dilakukan diversifikasi produk berbahan dasar pisang. Setelah dilakukannya sosialiasi, dilanjutkan dengan praktik pembuatan permen jelly. Praktik ini dimulai dengan menjelaskan bahan dan peralatan yang digunakan
\end{abstract}


sampai dengan proses pembuatan permen jelly. Dengan adanya kegiatan ini diharapkan ibu-ibu rumah tangga dapat memproduksi permen jelly dari buah pisang untuk dijual sehingga dapat meningkatkan pendapatan masyarakat terutama bagi ibu-ibu rumah tangga yang ada di Desa Kotaraja Kecamatan Sikur Lombok Timur.

Kata Kunci: buah pisang, diversifikasi produk, permen jelly, Desa Kotaraja

DOI: $10.29303 /$ abdimassangkabira.v2i1.70

\section{Pendahuluan}

Desa Kotaraja merupakan bagian dari wilayah Administratif pemerintahan kecamatan Sikur. Jarak Desa Kotaraja sekitar 7 km dari kota kecamatan dengan waktu tempuh 8 menit, sementara jarak ke kota kabupaten sekitar 17 km, dengan waktu tempuh tempuh 17 Menit. Adapun letak Desa Kotaraja berbatasan dengan sebelah utara Desa Tete Batu, sebelah selatan dengan Desa Loyok, sebelah timur berbatasan dengan Desa Gelora, dan sebelah barat berbatasan dengan Desa Pringga Jurang kecamatan Montong Gading. Wilayah Desa Kotaraja, terdiri dari dataran rendah dengan luas lahan adalah: $360.980 \mathrm{ha} / \mathrm{m}^{2}$. Kotaraja adalah salah satu desa di Kecamatan Sikur yang memilki potensi yang besar di bidang pertanian dan perkebunan. Potensi yang besar tersebut didukung dengan hamparan lahan yang luas.

Hasil perkebunan ini dapat dimanfaatkan menjadi produk-produk yang memiliki nilai ekonomi tinggi. Salah satu hasil perkebunan di Desa Kotaraja yaitu pisang. Pisang merupakan komoditas hortikultura (buah) yang dapat dimakan langsung atau diolah. Namun tentunya pengkonsumsian pisang secara langsung ataupun diolah memiliki kelebihan masing-masing. Di Desa Kotaraja masih banyak mengkonsumsi pisang dalam keadaan segar ataupun pengolahan yang masih sederhana seperti direbus dan digoreng. Sehingga perlu adanya upaya diversifikasi dan peningkatan nilai ekonomi pangan olahan berbahan baku pisang menjadi produk olahan, salah satunya yaitu permen Jelly.

Permen Jelly merupakan salah satu jenis permen yang digemari oleh berbagai kalangan usia, khususnya anak-anak. Umumnya permen Jelly terbuat dari puree, air dan bahan pembentuk gel, sehingga berpenampakan jernih transparan serta mempunyai tekstur dengan kekenyalan tertentu. Untuk mengolah puree pisang menjadi permen Jelly dilakukan dengan cara mendidihkan campuran gula, puree, pisang dan penambahan gelling agent agar diperoleh tekstur yang kenyal dan penampilan yang transparan. Selama ini, umumnya permen Jelly dibuat dengan memanfaatkan puree, rempah-rempah, susu, dan lain-lain (Koswara, 2009).

Bahan pembentuk gel merupakan komponen penting dalam pembuatan permen Jelly, sehingga dalam pembuatan permen Jelly pisang 
ditambahkan gelatin yang berfungsi sebagai bahan pembentuk gel, pengikat air, pemantap emulsi dan bahan pengental. Bahan pembentuk gel yang digunakan dalam pembuatan permen Jelly memerlukan kondisi tertentu untuk membentuk gel dengan sempurna. Bahan pembentuk gel seperti pektin, agar-agar, karagenan, memerlukan kondisi asam untuk dapat membentuk gel sempurna. Sedangkan gelatin sebagai bahan pembentuk gel tidak bergantung pada kondisi asam. Permen Jelly yang dibuat dari pisang dengan penambahan gelatin dapat membentuk gel dengan cara mengikat air dan membentuk jaringan. Gelatin yang dilarutkan dalam air panas bersuhu $70-80^{\circ} \mathrm{C}$, setiap partikelnya akan menyerap air sehingga antar molekul gelatin menjadi kompak. Bila didinginkan, molekul gelatin yang telah menyerap air akan mengurai menjadi jaringan melalui ikatan silang sehingga membentuk gel (Wiratmaja, 2006).

Pelaksanaan program pengabdian masyarakat ini akan diberikan kepada anggota Kelompok Dasa Wisma ARMAWA Desa Kotaraja. Kelompok ini beranggotakan ibu-ibu rumah tangga. Kegiatan ini melibatkan mahasiswa Universitas Mataram. Dengan adanya peningkatan nilai ekonomi hasil perkebunan, yaitu pisang diharapkan dapat meningkatkan pendapatan khususnya ibu-ibu rumah tangga dan masyarakat pada umumnya.

\section{Metode}

\section{Sosialisasi Pembuatan Permen Jelly}

Sosialisasi pembuatan permen jelly dari pisang dilakukan dihadapan anggota kelompok Dasa Wisma ARMAWA Desa Kotaraja. Kegiatan ini memberikan penjelasan tentang peningkatan nilai ekonomi pisang. Untuk dapat meningkatkan nilai ekonomi harus dilakukan diversifikasi produk berbahan dasar pisang. Salah satu yang dilakukan yaitu membuat permen jelly. Permen Jelly merupakan salah satu jenis permen yang digemari oleh berbagai kalangan usia, khususnya anak-anak. Umumnya permen Jelly terbuat dari puree, air dan bahan pembentuk gel, sehingga berpenampakan jernih transparan serta mempunyai tekstur dengan kekenyalan tertentu.

Bahan pembentuk gel merupakan komponen penting dalam pembuatan permen Jelly, sehingga dalam pembuatan permen Jelly pisang ditambahkan gelatin yang berfungsi sebagai bahan pembentuk gel, pengikat air, pemantap emulsi dan bahan pengental. Bahan pembentuk gel yang digunakan dalam pembuatan permen Jelly memerlukan kondisi tertentu untuk membentuk gel dengan sempurna. Bahan pembentuk gel seperti pektin, agar-agar, karagenan, memerlukan kondisi asam untuk dapat membentuk gel sempurna. Sedangkan gelatin sebagai bahan pembentuk gel tidak bergantung pada kondisi asam. Permen Jelly yang dibuat dari pisang dengan penambahan gelatin dapat membentuk gel dengan cara mengikat air dan membentuk jaringan. Gelatin yang dilarutkan 
dalam air panas bersuhu $70-80^{\circ} \mathrm{C}$, setiap partikelnya akan menyerap air sehingga antar molekul gelatin menjadi kompak. Bila didinginkan, molekul gelatin yang telah menyerap air akan mengurai menjadi jaringan melalui ikatan silang sehingga membentuk gel (Wiratmaja, 2006).

\section{Praktik Pembuatan Permen Jelly}

Bahan-bahan yang digunakan: Pisang Kepok, gelatin, sukrosa, glukosa, asam sitrat, pewarna makanan, tepung maizena, dan air.

Peralatan yang diperlukan adalah:

- Timbangan

- Kompor

- Loyang

- Pisau

- Sendok

- Blender

- Baskom

- Nampan

- Teflon

- Panci

- Saringan

Cara pembuatannya:

1. Pisang Kepok dipersiapkan terlebih dahulu

2. Dilakukan pengupasan yang diikuti peencucian terhadap pisang tersebut

3. Setelah itu dilakukan pemotongan dengan ukuran kecil

4. Pengukusan

5. Setelah matang, ditimbang seberat 100 gram lalu dilakukan penghalusan dengan cara diblender.

6. Setelah smenjadi bubur pisang,

7. Ambil bubur pisang seberat $200 \mathrm{ml}$, lalu masak dengan suhu 90 sampai 100 derajat Celcius selama 5 menit

8. Setelah mendidih lakukan pengadukan selama 5 menit hingga matang

9. Siapkan Cetakan atau Loyang dengan tebal $2 \mathrm{~cm}$

10. Tumpahkan bubur pisang yang sudah matang ke dalam cetakan tersebut

11. Lakukan pendinginan

12. Setelah dingin potong dengan ukuran $2 \times 2 \mathrm{~cm}$

13. Lakukan Pengeringan dan pengemasan

14. Permen Jelly siap disajikan

\section{Hasil Kegiatan}

Pelaksanaan kegiatan pengabdian kepada masyarakat tentang pemanfaatan hasil perkebunan (pisang) menjadi produk olahan (permen jelly) untuk meningkatkan pendapatan masyarakat di Desa Kotaraja 


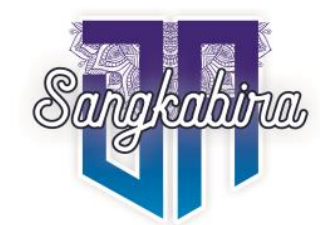

Vol. 2, No. 1, Desember 2021

Kecamatan Sikur Lombok Timur sesuai dengan rencana. Hal ini dapat dilihat dari antusiasme peserta dalam sosialisasi dan praktik pembuatan permen jelly yang difasilitasi oleh tim pengabdian masyarakat Universitas Mataram.

\section{Sosialisasi pembuatan Permen Jelly}

Sosialiasi ini dilakukan di hadapan ibu-ibu rumah tangga Kelompok Dasa Wisma ARMAWA di Desa Kotaraja. Dengan dilakukan sosialisasi ini diharapkan dapat menimbulkan minat dari peserta sosialisasi untuk memanfaatkan buah yang merupakan potensi lokal yang ada di desa tersebut. Pengolahan buah pisang yang selama ini dilakukan hanya dengan cara merebus atau menggorengnya saja. Dengan adanya sosialisasi ini diharapkan peserta bisa meningkatkan nilai ekonomi dari buah pisang dengan cara pengolahan buah pisang menjadi permen jelly.

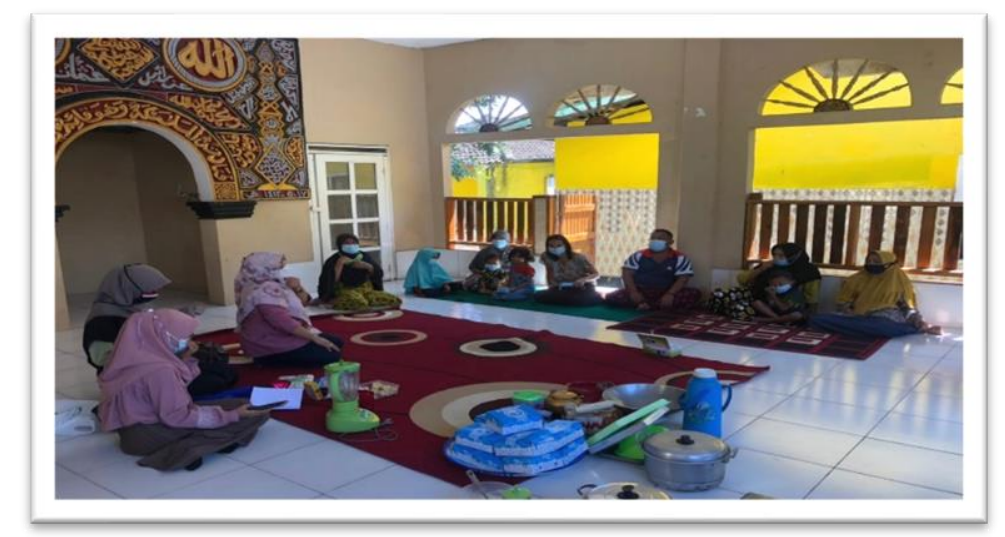

Gambar 1. Sosialisai Pembuatan Permen Jelly

\section{Praktik Pembuatan Permen Jelly}

Praktik pembuatan permen jelly dari buah pisang merupakan sesuatu yang baru bagi masyarakat terutama ibu-ibu rumah tangga yang ada di Desa Kotaraja. Hal ini terlihat dari antusiasme ibu-ibu rumah tangga yang ingin ikut membantu dalam pelaksanaan kegiatan ini. Praktik pembuatan permen jelly dari buah pisang dilakukan dalam 2 (dua) kegiatan. Kegiatan Pertama dilaksanakan oleh Tim Pengabdian Masyarakat dari Universitas Mataram. Kegiatan ini diiikuti oleh 13 (tigabelas) orang peserta. Kegiatan kedua dilaksankan dibawah Koordiantor ARMAWA diikuti oleh 10 (sepuluh) orang peserta.

\section{Kegiatan Pertama}

Praktik pembuatan permen jelly yang dilakukan oleh tim pengabdian Universitas Mataram dan Koordinator ARMAWA merupakan kegiatan yang ditunggu-tunggu oleh masyarakat. Hal ini terlihat dari antusiasme masyarakat yang ingin ikut membantu dalam pelaksanaan kegiatan ini. Kegiatan ini diawali dengan menjelaskan peralatan dan bahan-bahan yang diperlukan dalam pembuatan permen jelly. 
Alat dan Bahan:

Alat-alat yang digunakan untuk pembuatan permen jelly pisang antara lain timbangan, kompor, loyang, pisau, sendok, blender, nampam, panci, baskom dan teflon. Sedangkan bahan utama yang digunakan adalah pisang kapok dan gelatin sapi. Bahan tambahan yang digunakan adalah gula merk gulaku, asam sitrat merk gajah, vanilla essence merk Redbell, tepung maizena merk maizenaku, dan air.

Pembuatan bubur pisang:

1. Sortasi

Pisang yang akan digunakan dalam pembuatan bubur adalah pisang yang tidak terlalu matang.

2. Pencucian

Pisang kemudian dicuci pada air yang mengalir sambil digosok supaya getah dan kotoran yang menempel hilang.

3. Pengukusan

Pisang dikukus pada suhu 100 derajat celcius selama 5 menit.

4. Pengupasan

Pisang yang sudah dikukus dibiarkan dingin terlebih dahulu dan selanjutnya dikupas.

5. Penimbangan

Pisang yang telah dikukus dan dikupas kemudian ditimbang seberat 100 gr.

6. Penghalusan

Pisang diblender dengan ditambah air sebanyak 100 ml, sehingga menjadi bubur.

Pembuatan permen jelly:

1. Pemasakan

Pembuatan permen jelly pisang, bahan seperti 200 gr bubur pisang, $100 \mathrm{gr}$ gula, $5 \mathrm{gr}$ vanilla essence, dan 0,4 gr asam sitrat dimasukkan ke dalam panci, kemudian dimasak dengan suhu 90 - 100 derajat celcius selama 5 menit.

2. Pemasakan dan pengadukan

Selanjutnya penambahan gelatin sebanyak $70 \mathrm{gr}$. Gelatin dilarutkan dalam 75 ml air mendidih, kemudian dimasak dengan suhu 100 derajat celcius dan diaduk sehingga mengental dan tercampur rata selama 5 menit.

3. Pencetakan

Setelah itu, hasil yang diperoleh dituangkan kedalam Loyang ketebalan $2 \mathrm{~cm}$.

4. Pendinginan I 
Permen jelly pisang yang telah dicetak ke dalam loyang selanjutnya didiamkan pada suhu ruang yaitu sekitar 25 derajat celcius selama 30 menit untuk menurunkan suhu permen jelly tersebut.

5. Pendinginan II

Setelah suhu permen jelly turun menjadi suhu ruang, kemudian permen jelly dimasukkan ke dalam lemari es selama kurang lebih 2 jam untuk mempercepat terbentuknya tekstur gel.

6. Pemotongan

Permen jelly pisang yang telah mengeras dipotong bentuk dadu dengan ukuran $2 \times 2 \mathrm{~cm}$.

7. Pelapisan

Pelapisan dilakukan dengan melapisi permen jelly pisang menggunakan tepung maizena yang telah disangrai sebanyak 200 gr. Tujuan dari pelapisan agar permen jelly tidak terlalu lengket.

8. Pengemasan

Permen jelly pisang yang sudah dilapisi tepung maizena dan dikeringkan selanjutnya dikemas menggunakan kemasan plastik standing pouch.

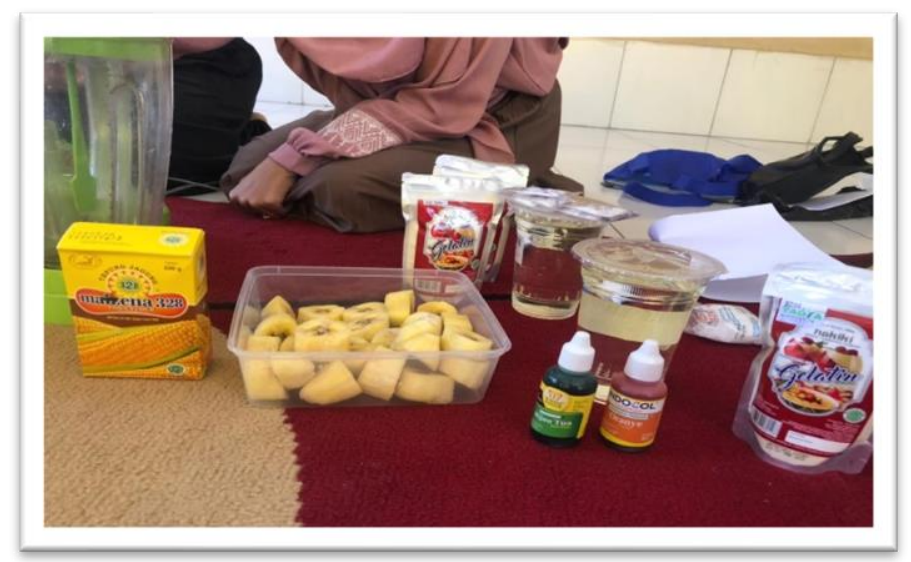

Gambar 2. Bahan-Bahan Untuk Pembuatan Permen Jelly 


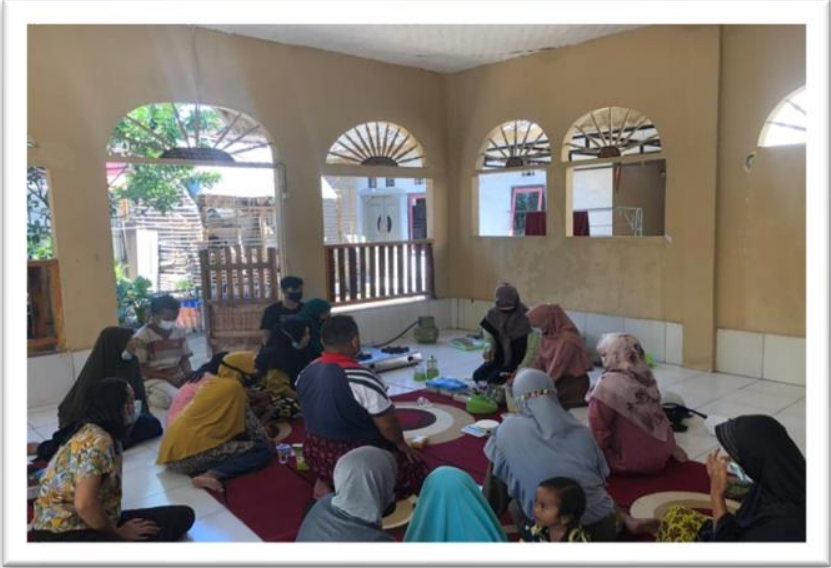

Gambar 3. Praktik Pembuatan Permen Jelly

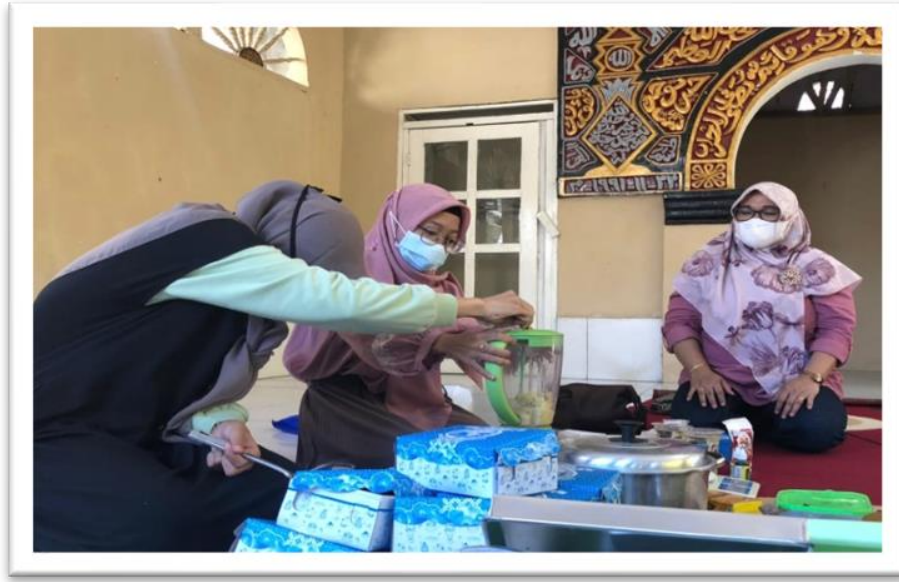

Gambar 4. Proses Penghalusan Pisang Yang Sudah Direbus

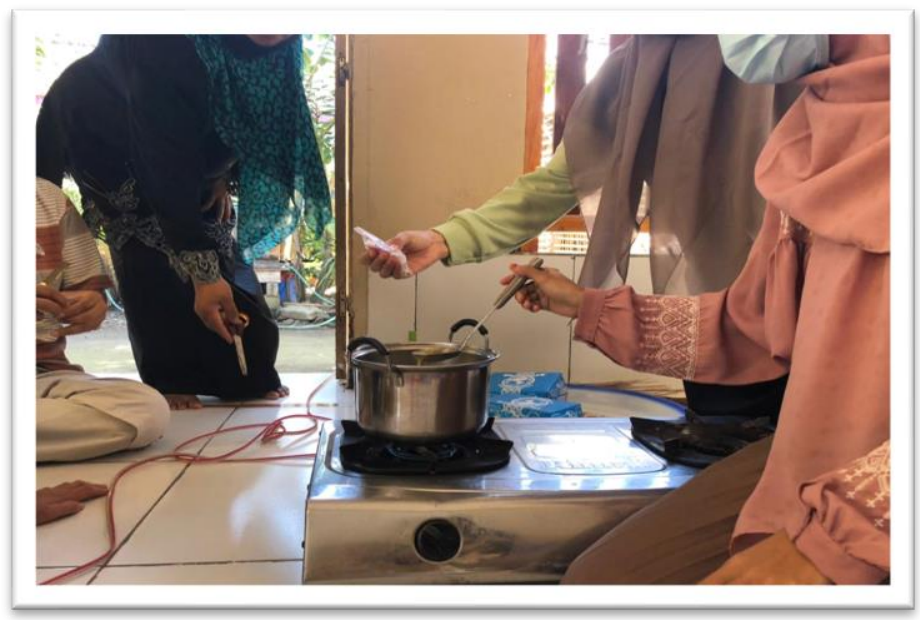

Gambar 5. Proses Pencampuran Bahan-Bahan 


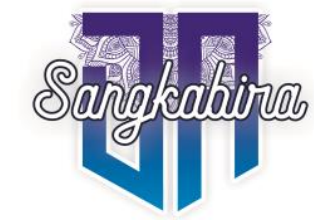

Vol. 2, No. 1, Desember 2021

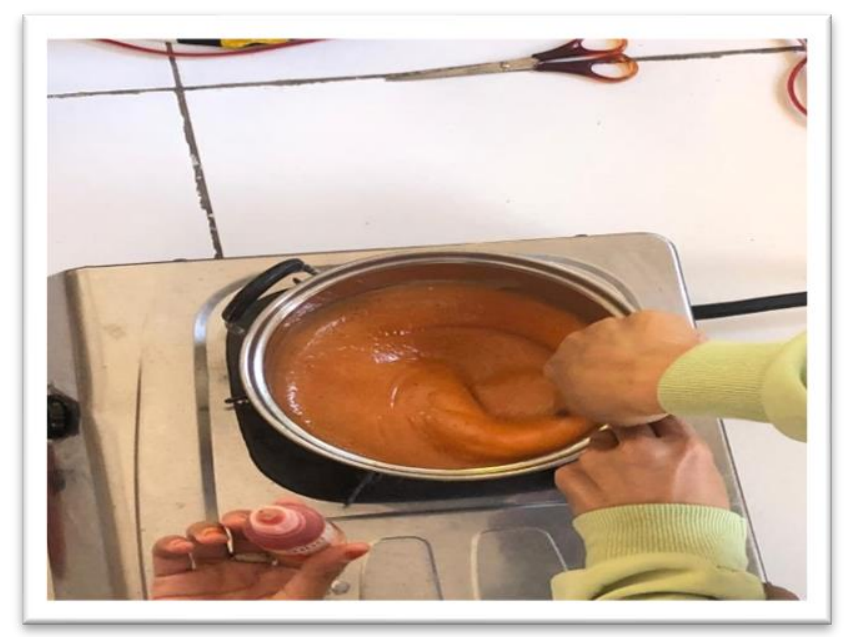

Gambar 6. Proses Pengadukan Hingga Matang

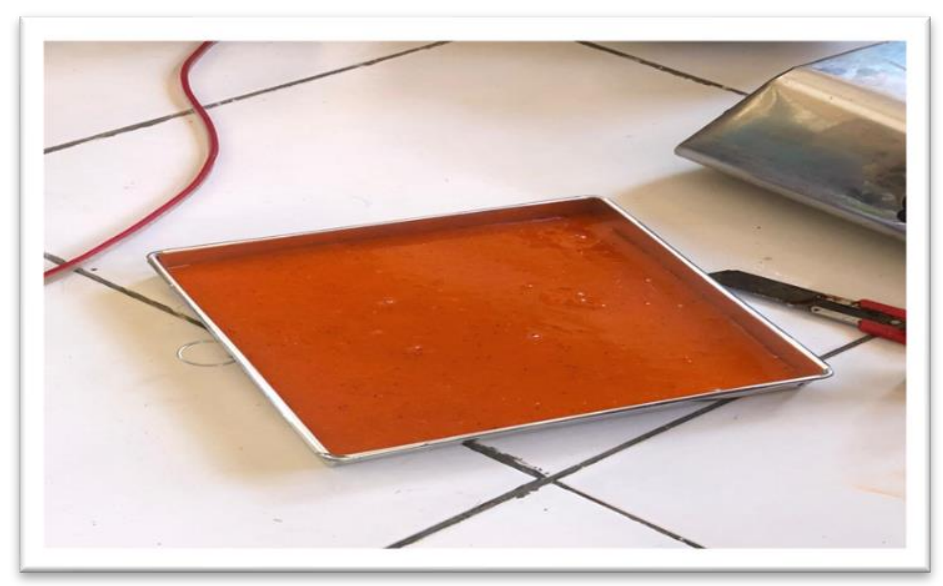

Gambar 7. Adonan yang sudah matang ditumpahkan ke loyang dan siap untuk dipotong-potong lalu disajikan 


\section{Kegiatan Kedua}

Kegiatan kedua dilaksanakan dibawah Koordinator ARMAWA yang diikuti oleh 10 (sepuluh) orang peserta.

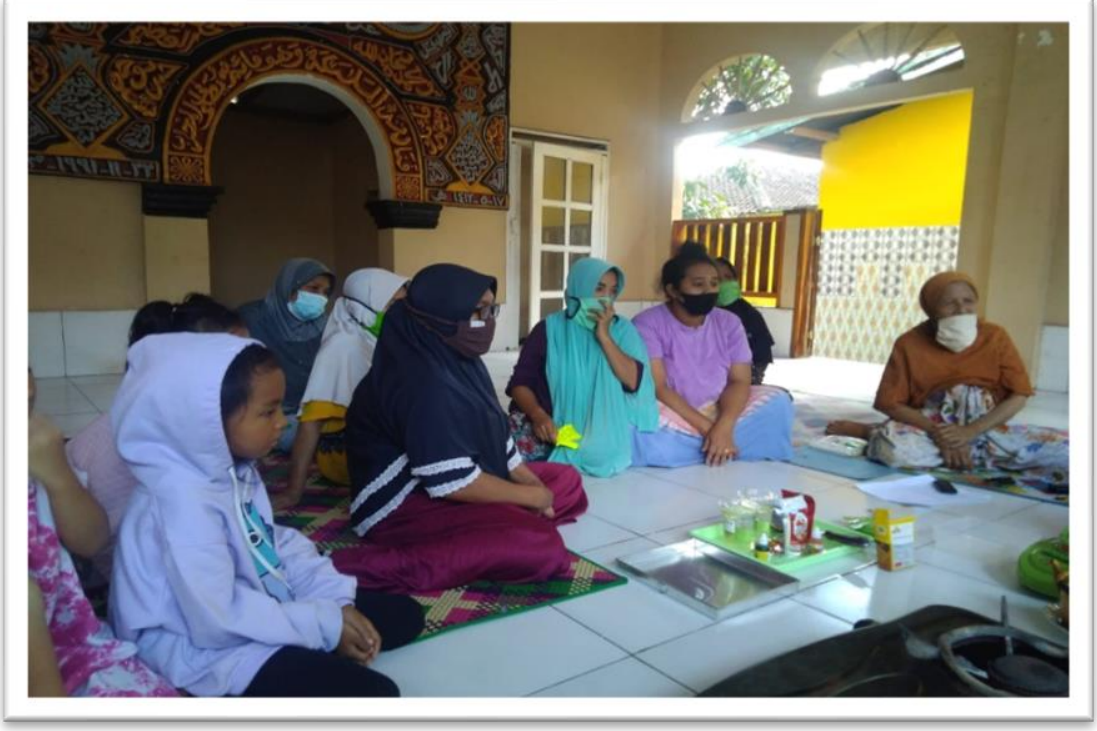

Gambar 8. Suasana Praktik Pembuatan Permen Jelly pada Kegiatan yang Kedua

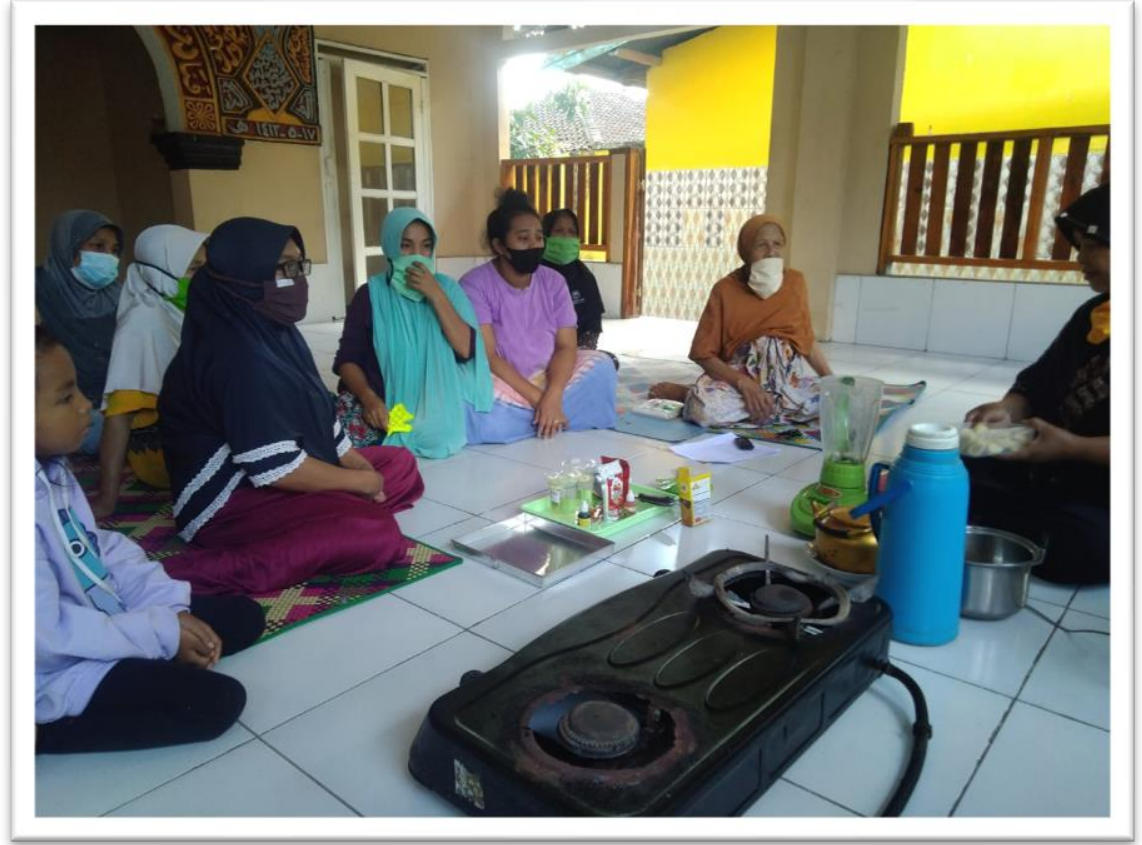

Gambar 9. Persiapan Penghalusan Pisang yang Sudah di Rebus 


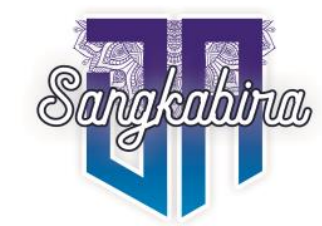

Vol. 2, No. 1, Desember 2021

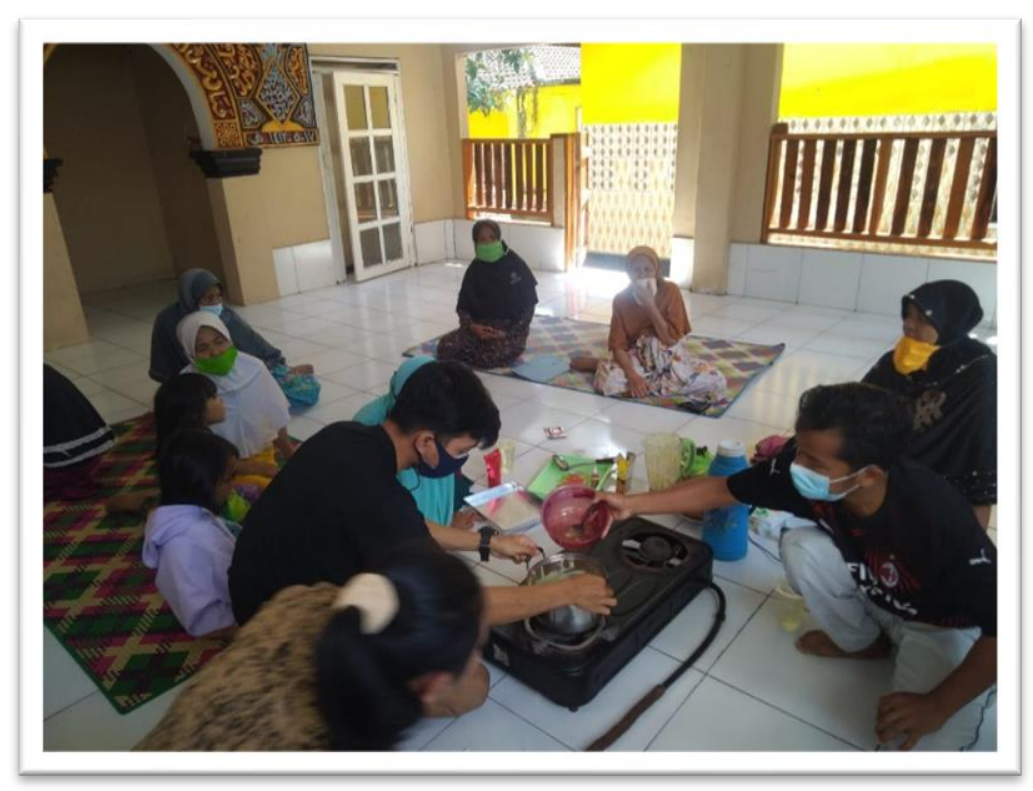

Gambar 10. Proses Pencampuran Bahan-Bahan

Peserta yang mengikuti kegiatan kedua ini berbeda dengan peserta yang mengikuti kegiatan pertama. Hal ini dilakukan agar lebih banyak masyarakat khususnya ibu-ibu rumah tangga mengetahui tentang pembuatan permen jelly dari buah pisang. Setelah mengikuti kegiatan ini diharapkan para peserta dapat mempraktikkan pembuatan permen jelly. Hasil dari kegiatan ini yaitu berupa permen jelly dapat dikonsumsi sendiri dan dijual untuk meningkatkan pendapatan keluarga

\section{Kesimpulan}

1. Pelaksanaan kegiatan pengabdian masyarakat tentang peningkatan nilai ekonomi pisang menjadi permen jelly untuk meningkatkan pendapatan masyarakat di Desa Kotaraja Kecamatan Sikur Lombok Timur sesuai dengan rencana. Hal ini dapat dilihat dari antusiasme peserta dalam kegiatan sosialisasi dan praktik pembuatan permen Jelly.

2. Masyarakat terutama ibu-ibu rumah tangga mengetahui bagaimana pembuatan permen jelly dengan menggunakan buah pisang. Diversifikasi produk yang berupa permen jelly merupakan produk baru yang dapat meningkatkan nilai ekonomi buah pisang. Selama ini, pengolahan buah pisang yang ada hanya sebatas direbus dan digoreng saja. Dengan adanya kegiatan ini diharapkan masyarakat terutama ibu-ibu rumah tangga dapat memproduksi permen jelly dari buah pisang untuk dijual sehingga dapat meningkatkan pendapatan masyarakat terutama bagi ibu-ibu rumah tangga yang ada di Desa Kotaraja Kecamatan Sikur Lombok Timur 


\section{Daftar Referensi}

Eva Fauziah, Esti Widowati, Windi Atmaka. 2015.Kajian Karakteristik Sensoris dan Fisikokimia Fruit Leather Pisang Tanduk (Musa corniculata) dengan Penambahan Berbagai Konsentrasi Karagenan. Jurnal Aplikasi Teknologi Pangan. Vol 4 (1): 11.

Koswara. S., 2009. Pengolahan Pangan dengan Suhu Rendah. http://tekpan.unimus.ac.id. Diakses pada tanggal 02 Desember 2018.

Putri, T.K. · D. Veronika - A. Ismail - A. Karuniawan - Y. Maxiselly ·A. W. Irwan W. Sutari. 2015. Pemanfaatan Jenis-jenis Pisang (Banana dan Plantain) Lokal Jawa Barat Berbasis Produk Sale dan Tepung. Jurnal Kultivasi Vol. 14(2).

Wiratmaja, H., 2006. Perbaikan Nilai Tambah Limbah Tulang Ikan Tuna (Thunnus sp) Menjadi Gelatin serta Analisis Fisika-Kimia. Skripsi.Institut Pertanian Bogor. Bogor.

https://id.wikipedia.org/wiki/Kota Raja, Sikur, Lombok Timur. Diakses pada tanggal 10 Desember 2018. 